\title{
Development of Cohesive Devices in Chinese Learners of English
}

\author{
Xiaojing Zhao \\ International School, East China Jiaotong University, Nanchang 330013, China \\ 694568458@qq.com
}

Keywords: Conjunctions; Rating scale; Development

\begin{abstract}
This paper explores a way to provide a language rating scale with empirical underpinnings. It examines the Common European Framework of Reference for Languages: Learning, Teaching, Assessment (CEF) scale for coherence and cohesion in the light of the analysis of Chinese learners' writing samples. The use of conjunctions in the summaries written by 23 Chinese learners of English is scrutinized to characterize the levels of the CEF scale. Stages of L2 writing development of coherence and cohesion can be inferred from the way Chinese learners used conjunctions at different levels of the scale. The use of conjunctions was found to be indicative of the ability of students to connect sentences and establish propositional relations. It is concluded that rating scales can benefit from an empirical study to confirm and evaluate the information represented in their descriptors and to adapt them to make them more useful for the scale users.
\end{abstract}

\section{Introduction}

Proficiency scales have served different purposes oriented towards the description of what the learners can do and how well he/she performs (North, 2000:19). They have been found limited in providing empirically validated statements in relation to what is known about second language development. Brindley (1998:126-32) suggests how various branches of second language acquisition and language testing research can contribute to prove if proficiency scale descriptors are related to second language development. This study, however, is to recognize the interface of language testing and second language acquisition in facilitating our understanding of language learning and assessment. It is addressed to add to that understanding by describing particular features of coherence and cohesion of English as Foreign Language (EFL) writing placed at different proficiency levels of the CEF1.

\section{Methodology}

The Subject Group. The essays were written by 23 Chinese learners of English who participated in a 4-week EAP course. Students were given special instruction and each had to take a written test at the beginning of the course and to submit an essay every week. Finally, they had also been required to summarize a reading passage using 200 words in 30 minutes in the written test. Students' written tests were used to identify the features of coherence at different levels of language proficiency in relation to conjunctions, while the two summaries corresponding to the last assignment were selected from each level to complement those features according to raters' judgments.

The Classification of the Data. Firstly, students were put into different placement. The three levels in which the summaries were placed corresponded to A2, B1 and B2 levels, being B1 level the one with more students. 
Table 1 Placement of students using the scale based on the CEF

\begin{tabular}{ll}
\hline CEF LEVEL & STUDENTS \\
\hline $\mathrm{B} 2$ & 2 \\
\hline $\mathrm{B} 1$ & $16^{2}$ \\
\hline $\mathrm{A} 2$ & 5 \\
\hline
\end{tabular}

Based on this classification, the features of coherence and cohesion of the 23 essays were then diagnosed.

Research Question. Are there any distinctive features in the use and type of conjunctions displayed in the Chinese learners' L2 writing at different levels of proficiency?Do the features identified in the analysis of conjunctions and the raters' statements match the descriptors of the rating scale?

Framework for the Analysis of the Data. One of the most salient aspects taken into account in the CEF scale are the cohesive devices, and the analysis of the conjunctions in the English as Second Language(ESL) texts can permit us to trace the development of this trait and compare it with the scale descriptors. This paper combines two types of taxonomies for the analysis: Hasan and Haliday's types of conjunctions (1976) and Mann and Thompson's types of relations (1987).

Results. Inter-rater reliability was calculated for the placement of the 23 summaries corresponding to the written test and for that of set A and B using Spearman's rank order correlation. The Spearman's rank order correlation was carried out to illustrate the statistically significant values between pairs of raters:

Table 2 Spearman's rank order correlation

\begin{tabular}{l|c|c|c|c|c} 
& $\mathrm{R} 1$ & $\mathrm{R} 2$ & $\mathrm{R} 3$ & $\mathrm{R} 4$ & $\mathrm{R} 5$ \\
\hline $\mathrm{R} 1$ & & & & & \\
$\mathrm{R} 2$ & 0.353 & & & & \\
R3 & 0.251 & & & & \\
R4 & 0.406 & 0.278 & 0.108 & & \\
R5 & & 0.363 & 0.175 & 0.361 & \\
\hline
\end{tabular}

**. Correlation is significant at the 0.01 level (2-tailed).

*. Correlation is significant at the 0.05 level (2-tailed).

The data showed a positive correlation among raters with high variability between them. The reliability coefficient for the written test placement using Ebel's formula was 0.60 which according to Cohen (cited in Pallant 2001:120), represents a large correlation among raters in the 0.5 to 1.0 range.

Fig. 1 below shows that the frequency of conjunctions tended to increase from level to level but there was a marginal change from level B1 to B2.

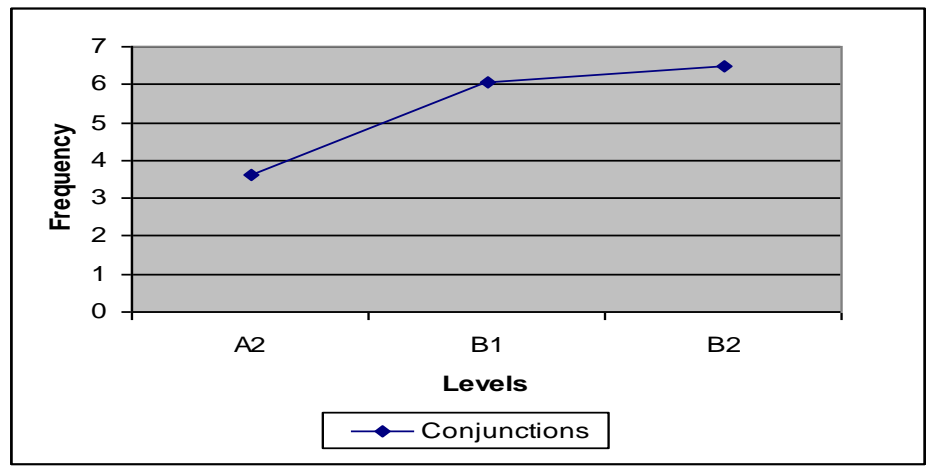

Figure 1. Average frequency of conjunctions per level 
As shown in the table below, the use of these cohesive devices increased in relation to additive and causal conjunctions but decreased with respect to adversative conjunctions. The mean comparison of temporal conjunctions fluctuated showing an increase from A2 to B1 and a slight decrease from B1 to B2.

Table 3 Descriptive statistics: conjunctions

\begin{tabular}{l|c|c|c|c|c|c}
\hline Group & Conjunctions & N & Minimum & Maximum & Mean & Std. Deviation \\
\hline \multirow{4}{*}{ A2 } & Additive & 5 & 0.00 & 1.00 & 0.2000 & 0.44721 \\
& Adversative & 5 & 1.00 & 4.00 & 2.0000 & 1.41421 \\
& Causal & 5 & 1.00 & 5.00 & 2.8000 & 1.64317 \\
& Temporal & 5 & 0.00 & 2.00 & 0.8000 & 1.09545 \\
& Continuative & 5 & 0.00 & 0.00 & 0.0000 & 0.00000 \\
\hline \multirow{4}{*}{ B1 } & Additive & 16 & 0.00 & 3.00 & 0.6250 & 0.95743 \\
& Adversative & 16 & 0.00 & 6.00 & 1.8125 & 1.72119 \\
& Causal & 16 & 0.00 & 7.00 & 3.1875 & 2.45544 \\
& Temporal & 16 & 0.00 & 6.00 & 2.1875 & 1.86971 \\
& Continuative & 16 & 0.00 & 0.00 & 0.0000 & 0.00000 \\
\hline \multirow{5}{*}{ B2 } & Additive & 2 & 1.00 & 1.00 & 1.0000 & 0.00000 \\
& Adversative & 2 & 0.00 & 1.00 & 0.5000 & 0.70711 \\
& Causal & 2 & 2.00 & 6.00 & 4.0000 & 2.82843 \\
& Temporal & 2 & 1.00 & 3.00 & 2.0000 & 1.41421 \\
& Continuative & 2 & 0.00 & 0.00 & 0.0000 & 0.00000 \\
\hline
\end{tabular}

Causal conjunctions appeared to have the higher mean values in all groups but also the highest standard deviations, which indicates that only few individuals in each group used them. Continuative conjunctions were not commonly used by the EFL students when writing the summary. According to Leech and Svartvik (1994:23) their use is more related to informal conversations rather than to the writing of academic prose. Only two continuative conjunctions were found in B1 level: sure and anyway.

Table 4 Conjunctions used in each level

\begin{tabular}{c|l|l|l}
\hline Conjunctions & \multicolumn{1}{|c|}{ A2 (N=5) } & \multicolumn{1}{c|}{ B1 (N=16) } & B2 (N=2) \\
\hline \multirow{2}{*}{ Additive } & Also, and, additional & $\begin{array}{l}\text { but also, in addition, that is, that's why, also, and } \\
\text { then, but also, for example, } \\
\text { or, such, and }\end{array}$ & $\begin{array}{l}\text { such, moreover, also, } \\
\text { furthermore }\end{array}$ \\
\hline Adversative & but, however, although, but in fact, even though, & although, even though, \\
& on the other hand, unfortunately & & however \\
\hline Temporal & from above, and now, all in & $\begin{array}{l}\text { at the same time, before, finally, meanwhile, } \\
\text { secondly, the second one, all in all, at the same } \\
\text { time, finally, first, first of all, firstly, now, } \\
\text { nowadays, second, secondly, the first one, } \\
\text { third, thirdly, to sum up, from above }\end{array}$ & $\begin{array}{c}\text { as mentioned above, } \\
\text { secondly, thirdly, to }\end{array}$ \\
\hline
\end{tabular}

This table comprises the raw data found in the EFL summaries. Also appears to be the additive conjunction that is most commonly used alongside the levels. And so is the most frequently used causal conjunction between the groups. There is no particular adversative or temporal conjunction that is present in all the levels. Nevertheless, levels B1 and B2 used the temporal correlative conjunctions secondly and thirdly, and the temporal conclusive to sum up. However was the adversative conjunction these two levels also had in common. The most reiterative conjunctions used in A2 level summaries were from above, and, if and also, being from above found twice in the 
same text. But also, firstly, secondly, and, in addition, although and so were repeated very often in the B1 texts. The conjunctions listed under the B2 level were used only once in the writings.

Regarding the propositional relations formulated by the conjunctions, it can be seen that the EFL students established more subject matter and presentational relations than multinuclear ones while they advanced in the scale.

Table 5 Descriptive statistics: propositional relations

\begin{tabular}{l|c|c|c|c|l|l}
\hline Group & Relations & N & MIN & MAX & Mean & Std. Deviation \\
& Subject matter & 5 & 0.00 & 1.00 & 0.4000 & 0.54772 \\
A2 & Presentational & 5 & 0.00 & 1.00 & 0.6000 & 0.54772 \\
& Multinuclear & 5 & 0.00 & 1.00 & 0.2000 & 0.44721 \\
& Subject matter & 16 & 0.00 & 9.00 & 2.3125 & 2.44182 \\
B1 & Presentational & 16 & 0.00 & 5.00 & 2.1250 & 1.58640 \\
& Multinuclear & 16 & 0.00 & 1.00 & 0.1875 & 0.40311 \\
& Subject matter & 2 & 3.00 & 3.00 & 3.0000 & 0.00000 \\
& Presentational & 2 & 2.00 & 3.00 & 2.5000 & 0.70711 \\
& Multinuclear & 2 & 0.00 & 0.00 & 0.0000 & 0.00000 \\
\hline
\end{tabular}

In this table, it is shown that A2 level students used more relations of the presentational kind and that B1 and B2 students established more subject matter relations. Subject matter and presentational relations were found to overlap during the analysis and the former took precedence because they are more likely to vary in a text as suggested by Mann and Thompson (1987). Subject matter relations were highly used in B2 level in comparison with A2 and B1. The table below displays the relations that were correctly established in each level:

Table 6 Relations used in each level

\begin{tabular}{l|l|l|l}
\hline \multicolumn{1}{c|}{$\begin{array}{c}\text { Coherence } \\
\text { relations }\end{array}$} & \multicolumn{1}{|c|}{ A2 (N=5) } & \multicolumn{1}{c}{ B1 (N=16) } & \multicolumn{1}{c}{ B2 (N=2) } \\
\hline Multinuclear & multinuclear restatement & contrast, joint, sequence & \\
\hline Presentational & motivation, summary & $\begin{array}{l}\text { antithesis, background, } \\
\text { evidence, summary }\end{array}$ & $\begin{array}{l}\text { concession, summary, } \\
\text { antithesis, evidence }\end{array}$ \\
\hline Subject matter & $\begin{array}{l}\text { elaboration, means, otherwise, } \\
\text { nonvolitional-result }\end{array}$ & $\begin{array}{l}\text { unconditional, elaboration, } \\
\text { evaluation, nonvolitional- } \\
\text { result, means, solutionhood }\end{array}$ & $\begin{array}{l}\text { elaboration, nonvolitional } \\
\text { result, otherwise, solutionhood }\end{array}$ \\
\hline
\end{tabular}

In the presentational category, summary relations were more frequently employed alongside the levels. Similarly, in the subject matter category, elaboration and nonvolitional-result relations were used in the three groups. Elaboration relations were the most highly used in each level. These cooccurring features linked to the commonly used conjunctions among the levels may be representative of the summary text type and mark its underlying functional dimension. In regard to each level, A2 was distinguished out of the other two levels in the use of the multinuclear restatement and motivation types. B1 employed some types of multinuclear relations and background and unconditional ones that were not used by any other group. B2 level displayed only one presentational relation that differed from the ones used in the other levels.

As can be seen from the information above, students appeared to use different classes of relations and consequently of conjunctions within each of the broader categories. An examination of the types of conjunctions and relations correctly used by the EFL students at different levels reflected their ability to manipulate certain conjunctions to create a certain number of coherent relations that can be associated to the summary text type. 


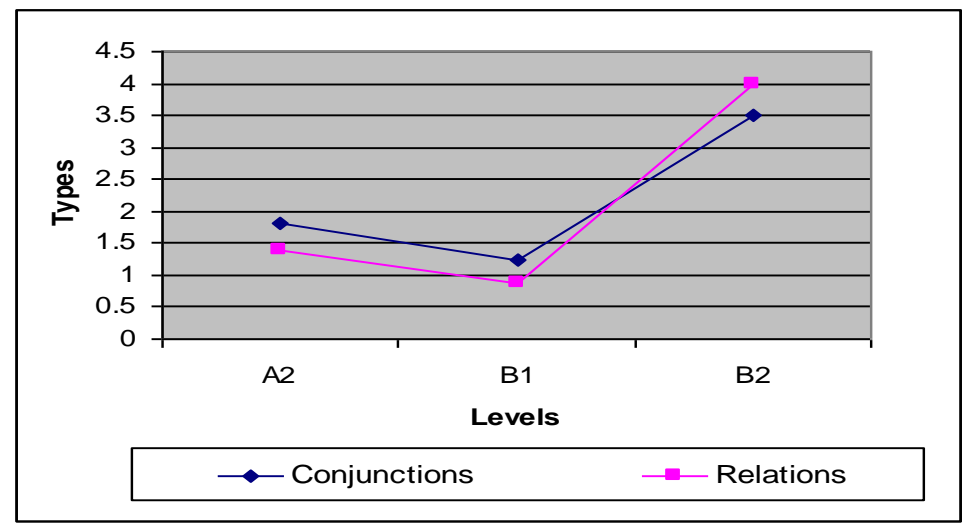

Figure 2. Types of conjunctions and propositional relations

The graph above suggests that diversity in the average type of conjunctions is higher than the diversity in the average kind of relations in levels A2 and B1. However, the number of types of conjunctions and coherent relations decreased in B1 and differed from those of A2. On the other hand, B2 students employed fewer types of conjunctions to establish more relations. This reflects a transition from the use of more types of conjunctions to express fewer relations and eventually use fewer types of conjunctions to establish more coherence relations while the number of conjunctions increased.

An analysis of the accuracy in the use of conjunctions represented in the production of coherent relations was carried out showing the following results:

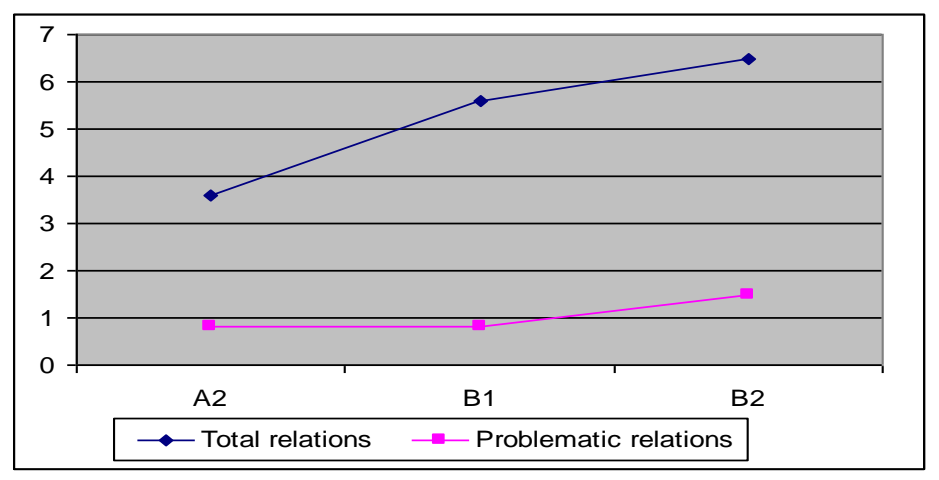

Figure 3. Means comparison of relations and problematic relations per level

This graph illustrates the average frequency per level in the use of relations in comparison with the average frequency per level of incorrect relations. The problematic relations are described in this study as those which do not match the conjunctions used by the students in a particular context and also to those established by an unnecessary conjunction. The problematic relations do not represent a big proportion of the total number of relations probably due to the size of the data. However, it is possible to identify a trend in the distribution along the levels which can be more significant in the analysis of a larger sample. The graph displays that A2 and B1 levels have the same range of problematic relations and that a sudden increase in the average mean of problematic relations appears in B2 level. In comparison with the average number of relations3, it can be observed that there is not a proportional relationship in terms of the quantity of relations and the number of errors per level. The increase of relations from level A2 to B1 was bigger than from B1 and $\mathrm{B} 2$, but there was no increase in the number of problematic relations from $\mathrm{A} 2$ to $\mathrm{B} 1$ as it actually happened from B1 to B2. This may be due to the kind of conjunctions ESL students employed in each level and the existing similarities or differences among the conjunctions. 
The features of coherence and cohesion represented in the use of conjunctions in the ESL summaries revealed mixed results regarding the frequency in the use of conjunctions, their problematic relations and the types of conjunctions and propositional relations. The results from the analysis of the raters' indigenous criteria unveiled a similar scenario about other aspects of coherence and cohesion as will be observed in the next section.

\section{Discussion}

The present study indicates that the frequency of conjunctions increased progressively by showing a later decline at B2. This suggests that the change in the use of conjunctions was more substantial from A2 to B1 than for B2. Indeed, this finding is consistent with previous studies(Homburg 1984, Ishikawa 1995 and Bardovi-Harlig 1992). It was also found that learners at lower levels relied on the same conjunction to express different ideas whereas higher level students employed a different conjunction for each idea. Schoonen et al. (2003:171) attribute this phenomenon to problems with the working memory for low-level learners to control higher-order processes.

Findings obtained from the analysis of the scale and of conjunctions intertwined particularly in two aspects: the increase in the number and variety of cohesive devices used in each level and the prevalent existence of problematic relations at higher levels, as stated in the descriptors for B2. It is clearly presented in the scale that there is a difference between the types of cohesive devices students can use from lower levels to higher ones. The rhetorical analysis corroborates these theoretical assumptions and teachers' perceptions on the use of cohesive devices, and informs about the ability of the students to manipulate conjunctions to produce coherent relations at three different levels of proficiency.

The empirical analysis of conjunctions is informative of the type of conjunctions and propositional relations that the Chinese students were able to use in their summaries. The focus of the analysis on conjunctions did not account neither for the examination of the organizational patterns and the clarity and smoothness of discourse in the texts in each level nor for the exploration of other cohesive devices. Insights on those aspects were extracted from the raters' judgments.

\section{Conclusions}

It is thus concluded that rating scales can benefit from an empirical study to confirm and evaluate the information represented in their descriptors and to adapt them to make them more useful for the scale users.

\section{Acknowledgments}

This work was supported by Jiangxi Social Science Project for 2013(13YY17) and Jiangxi Teaching Reform of of Higher Education Project for 2016(JXJG-16-5-32)

\section{References}

[1] Bardovi-Harlig, K (1992) A second look at T-unit analysis. Reconsidering the sentence, TESOL Quarterly, 26, pp. 390-395.

[2] Brindley, G, Describing language development? Rating scales and SLA, in Interfaces between second language acquisition and language testing research, ed. Bachman, L and Cohen, A (Cambridge, New York : CUP, 1998),113-139

[3] Grabe, W and Kaplan, R (1996) Theory and practice

[4] of writing : an applied linguistic perspective, New York: Longman. 
[5] Homburg,T (1984) Holistic evaluation of ESL compositions: Can it be validated objectively? In Wolfe-Quintero, K; Inagaki, S and Kim, H (1998) Second language development in writing: measures of fluency, accuracy and complexity, Hawai: University of Hawai Press

[6] Ishikawa, S (1995) Objective measurement of low-proficiency EFL narrative writing. Journal of Second Language Writing, 4, pp. 51-70

[7] Leech, G and Svartvick, J (1994) A communicative grammar of English, Singapore: Longman Group Limited.

[8] Mann, W and Thompson, S (1987) Rhetorical Structure Theory: A theory of text organization, University of Southern California, Information Sciences Institute (ISI)

[9] Murphy, T (2001) The emergence of texture: an analysis of the functions of the nominal demonstratives in an English interlanguage corpus, Language Learning and Technology, Vol. 5, No. 3. pp. 152-173

[10] North, B (2000) The development of a common framework scale of language Proficiency, New York: Peter Lang Publishing, Inc.

[11] Schoonen, R ;Glopper, k; Gelderen, A; Hulstijn; J; Snellings, P and Stevenson, M ( 2003) First language and second language writing: the role of linguistic knowledge, speed of processing and metacognitive knowledge, Language Learning, 53, 1, pp. 165-202 